\title{
Artificial Intelligence, Firm Resilience to Supply Chain Disruptions, and Firm Performance
}

\author{
Yulia Sullivan \\ Baylor University \\ Yulia Sullivan@baylor.edu
}

\author{
Samuel Fosso Wamba \\ Toulouse Business School \\ s.fosso-wamba@tbs-education.fr
}

\begin{abstract}
In today's uncertain and disruptive environment, every firm in the supply chain is susceptible to disruptions that may require high levels of firm resilience. We argue that recent advances in artificial intelligence (AI) may help. This paper expands our understanding of the role of $A I$ in shaping firm resilience to supply chain disruptions and, in turn, enhancing firm performance. In doing so, we conceptualize AI use as a dynamic information processing capability - consisting of three dimensions: coordinating/integration, learning, and strategic competitive response capability - as an antecedent of firm resilience to supply chain disruptions, and firm resilience as a mediation factor that links AI use and firm performance. By analyzing the data gathered using a two-stage survey from 107 companies in Europe, we found AI use has a direct impact on firm resilience, and firm resilience fully mediates the relationship between AI use and firm performance. The findings of this study contribute to IT and supply chain literature.
\end{abstract}

\section{Introduction}

In today's uncertain and disruptive environment, every firm is susceptible to disruptions [1]. The notion of organizational resilience-the ability of an organization to successfully confront the unforeseenhas always been a core element of success when disruptions take place $[1 ; 2]$. However, given the numbers and types of threats that can undermine a supply chain are now greater than ever, resilience has taken on even more significance in supply chain management. A supply chain disruption may interrupt the flow of goods and services offered by organizations [3]. Consequently, disruptions in the supply chain can have negative consequences on firm performance, lowering both stock returns and firms' competitive positioning in the markets [4]. For example, many manufacturers from various industries are struggling to manage the COVID-19 pandemic's growing impact on their supply-chains. Some companies, such as General Motors, have extensively mapped their supply chains throughout the years. When the pandemic hit, those companies that had mapped their supply chain already knew which parts and materials were originating in the Wuhan and Hubei areas. As a result, they were able to bypass the frantic hunt for information and fast-track their responses [5]. Realizing that disruptions in the supply chain can have negative consequences, firms are now focusing on building resilience in order to mitigate the impact of future disruptions $[1 ; 6]$.

Prior research has acknowledged the difficulty in predicting and detecting the disruptions may vary depending on the type and nature of disruptions [4]. New technologies, such as artificial intelligence (AI), have provided a new way for organizations to enhance their resilience. AI's ability to analyze huge volumes of data, understand relationships, provide visibility into operations, and support better decision making enables organizations to adapt to variability effects due to disruptions in a timely manner [7]. Although anecdotal evidence has pointed toward the benefits of AI to accurately predict inventories and provide flexibility to supply chain during a disruptive event, there is limited research on the role of AI in enhancing firm resilience. Although prior studies have argued that technology can strengthen supply chain resilience under uncertainty, and in turn, firm performance (e.g., [8]), AI offers greater advantage as it may accelerate the decision process in identifying, prototyping, and testing novel solutions [9]. In this current study, our goal is to understand how AI can make organizations more resilient to supply chain disruptions and, in turn, improve their firm performance. Studying resilience that focuses on the supply chain domain can help organizations overcome disruptions in the future.

AI is typically defined as "the ability of machines to perform human-like cognitive tasks" [10, p. i]. Organizations are deploying a range of AI tools and solutions such as machine learning and deep-learning to improve their forecast accuracy and detect problems at an early stage [11]. AI, if used strategically to process information and reconfigure organizational resources, can help reduce complexity and uncertainty [12]. There are already a number of research studies suggesting that AI can perform as well as or even better than humans at key business tasks, such as performing financial 
transactions, scheduling complex logistics, and forecasting technology development [13]. Thus, the importance of AI for creating value in organizations should not be understated.

Drawing upon the dynamic capabilities theory [14], we propose and test a model that conceptualizes AI use as a dynamic organizational information processing capability. We assert that AI use directed toward the coordinating/integration, learning, and strategic competitive response capability [11] will have a direct impact on firm resilience to supply chain disruptions. These three inter-related dimensions jointly facilitate the creation and deployment of new configurations - a critical way to manage risk and recover from a supply chain disruptions [1]. Thus, they can be understood as subdimensions of a more complex, abstract construct representing dynamic capabilities [15]. Having argued that AI use directed toward coordinating/integration, learning, and competitive response processes is significant for firms to be resilient to supply chain disruptions, we expect to find that firm resilience mediates the relationship between AI use and firm performance - although the direct effect is possible.

To test our research model, we conducted a twostage study among business and IT executives in France and UK. As a whole, the integrative research model of AI usage and its influence on firm resilience and firm performance developed in our study offers a theoretical background and explanation in the area of AI that has become widely desirable, and yet, continues to remain understudied.

\section{Theoretical Background}

\subsection{Artificial Intelligence (Concepts and Definitions)}

Organizations are increasingly using AI that opens up new possibilities for the relationship between human and machines to perform tasks on digital platforms [16]. In this paper, we define AI as the ability of a system to acquire learnings by analyzing the external environment's data and using acquired learnings to adjust or make new plans against environmental changes [17]. This includes deriving patterns from data using algorithms (i.e., machine learning for text analytics, predictive model) [18] and using Robotic Automation as well as virtual agents to support business processes [19]. Although at the operational level, there are different forms of AI (e.g., supervised, unsupervised AI), we do not distinguish among different types of AI. Instead, our conceptualization of AI focuses on its ability to acquire learning as we defined earlier.

The growing computational AI capabilities are dynamic; they overlap with different sociotechnical and data-related entities [20]. For this reason, we explain the role of AI in organizations from the information processing perspective. Organization information processing theory characterizes business firms as open social systems that seek to execute business strategies through mitigating uncertainty in decision-making processes $[21 ; 22]$. According to this theory, necessary amount of information is required to satisfy decision making for a particular set of objectives [21]. Organizations with high information processing capability are able to gather, interpret, and synthesize information in a meaningful fashion that supports decision making [22]. AI systems are likely to complement or even replace human decision-making. For example, AI techniques, such as machine learning and robust estimation, are able to overcome human's cognitive information processing constraints and deal with a more considerable amount of data while detecting patterns. In turn, they allow human users to generate new ideas in support of human-machine interaction during problem analysis [9].

\subsection{AI Use as A Dynamic Information Processing Capability}

Teece et al. [14] developed the notion of dynamic capabilities and argued that dynamic capabilities reflect "the capability to renew competences so as to achieve congruence with the changing environment" (p. 515). Dynamic capabilities enable organizations to integrate, build, and reconfigure their resources and competencies [14]. In an effort to understand the nature of dynamic capabilities, prior research has suggested the difference between ordinary and dynamic capabilities. Whereas ordinary capabilities can best be thought of as "achieving technical efficiency and "doing things right" in the core business functions of operations, administration, and governance" [23, p. 331], dynamic capabilities "help enable an enterprise to profitably build and renew resources and assets that lie both within and beyond its boundaries, reconfiguring them as needed to innovate and respond to (or bring about) changes in the market and in the business environment more generally" [23, p. 332].

According to Protogerau et al. [15], there are three core processes underlying dynamic capabilities: (1) coordinating/integration; (2) learning; and (3) strategic competitive response processes. An organization's applications of AI across their supply chain enable greater dynamic information processing capability that can be used to gather and interpret data, enabling organizations to easily allocate resources and tasks [10]; establish knowledge creation routine (learning) [18]; and reduce uncertainty by stimulating insights [24]. AI also provides businesses with unprecedented 
opportunities for designing intelligent products, devising novel service offerings, and inventing new business models [25]. These AI capabilities reflect the key characteristics of dynamic capabilities.

We argue that for the information processing capability of AI to provide solutions for supply chain issues, it has to be directed toward the coordinating/integration, learning, and strategic competitive response processes. These three processes act jointly to facilitate the creation and deployment of new configurations of resources [15]. For example, AIbased data-driven solutions may promote real-time coordination, enhancing supply chain collaboration and visibility. Such solutions will place the organization in a better position to implement innovative supply chain resilience strategies needed when a disruptive event comes. In turn, AI provides decision makers with knowledge to produce better resource configurations and reconfigurations that enhance firm resilience to supply chain disruptions.

Coordinating/integration describes the firm ability to use and assess the value of existing resources and integrate them to shape new capabilities [15]. Coordinating/integration involves an effective coordination of a variety of tasks and resources and the synchronization of different activities [15]. We argue that the information processing power of AI can facilitate this coordination capability by augmenting human skills to organize and coordinate organizational core activities. This coordination capability could "lead organizations toward dynamic organizing and competitive advantage upon the introduction of intelligent technologies" [26, p. 15]. Some authors even argue that AI can "enable organizations to divide and allocate tasks as well as to integrate efforts in novel ways" [27, p. 67]. AI enables the integration of business systems with business or manufacturing operations that reduces process variation and improves global optimization [28].

Learning capability refers to the firm ability to explore and learn new ways while at the same time exploit what have already learned [15]. Processing information using AI can support organizational learning and enable firms to form and execute business strategies effectively [29]. For example, firms may use AI to assess potential key enablers of changes in supply and demand [26], identify patterns and correlations, and create a new form of organizational control (e.g., evaluations by users) [27]. Organizations that learn with AI can refine business processes quickly as circumstances changes [12]. As people in an organization continue to learn, their perception of a problem may change. When this happens, AI systems can be realigned with humans' current problem understanding to facilitate learning [18]. Therefore, organizational learning supported by AI's information processing capability is an important process, which through an interaction with human users, leads to increased firm performance [12].

Strategic competitive response capability refers to the firm ability to scan the environment, identify new opportunities, assess its competitive position, and respond to competitive strategic moves [15]. AI is increasingly capable of outperforming humans in terms of quickly responding to changing and complex situations [30]. AI can generate insights that firms can use in a decision processes [12]. For example, machinelearning applications are being used to detect patterns in vast volumes of data and interpret their meaning [19]. Such insights can influence an array of business activities, including operations, revenue targets, performance management, and marketing [12].

In sum, the preceding arguments indicate that AI's information processing capability applied in three core areas: coordination, learning, and strategic competitive response can facilitate changes within an organization. Thus, they can be understood as subdimensions of a more complex, abstract construct representing dynamic capabilities [15].

\section{Research Model}

Our proposed model is shown in Figure 1. Based on our earlier discussion, the use of AI in the areas of coordinating/integration, learning, and strategic competitive response (i.e., we use the term "AI use" for brevity) is considered a dynamic capability that will affect firm resilience to supply chain disruptions. We also suggest that firm resilience will mediate the relationship between AI use and firm performance.

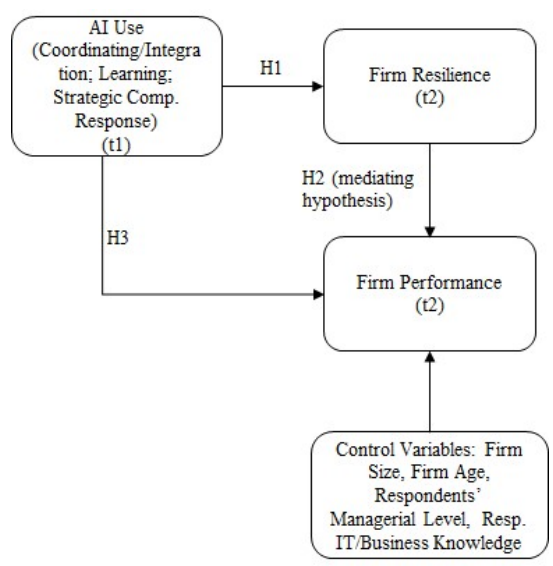

Figure 1. Research Model

Our study mainly focuses on the supply chain resilience (i.e., external resilience) because from the 
practical view, relative to internal operations, it is more difficult for firms to control external activities and to recover from disruptions with their suppliers and customers in unpredictable environments [8]. Further, given we assess the use and value of AI in the supply chain domain of organizations, we examine the operational aspect of firm performance (i.e., operational performance) as the dependent variable. We also include the following control variables-firm size, firm age, respondent's executive level, respondents' IT knowledge, and business knowledge-for firm performance. The construct's definitions are summarized in Table 1.

\section{Table 1. Constructs' Definition}

\begin{tabular}{|c|c|}
\hline Construct & Definition \\
\hline AI use & $\begin{array}{l}\text { A dynamic organizational information } \\
\text { processing capability reflected in three } \\
\text { processes: (1) coordinating/integration: } \\
\text { assess the value of value of existing } \\
\text { resources and integrate them to shape } \\
\text { new capabilities; (2) learning: explore } \\
\text { and exploit internal and external } \\
\text { knowledge; and (3) strategic competitive } \\
\text { response: scan the environment, identify } \\
\text { new opportunities, and assess firm's } \\
\text { competitive response. }\end{array}$ \\
\hline $\begin{array}{l}\text { Firm } \\
\text { resilience to } \\
\text { supply chain } \\
\text { disruptions }\end{array}$ & $\begin{array}{l}\text { The capacity of organizations to } \\
\text { anticipate, overcome, and recover from } \\
\text { supply chain disruptions quickly [1]. }\end{array}$ \\
\hline $\begin{array}{l}\text { Firm } \\
\text { performance }\end{array}$ & $\begin{array}{l}\text { Measured as operational performance- } \\
\text { measurable aspects of the outcomes of an } \\
\text { organization's processes, including } \\
\text { timeliness of delivery, high-quality } \\
\text { supply, response time, operating } \\
\text { efficiency, and process improvement } \\
{[31] \text {. }}\end{array}$ \\
\hline
\end{tabular}

\subsection{AI Use and Firm Resilience}

We predict that AI use will lead to high firm resilience. Firm resilience refers to the capacity of organizations to anticipate, overcome, and recover from supply chain disruptions quickly [1]. Examples of supply chain disruptions range from Hurricane Katrina in 2006, or the tsunami in Japan in 2011 to newer examples of disruptions, such as the COVID-19 pandemic. These events caused a remarkable number of supply chain disruptions, resulting in long delivery delays, decreases in revenues and sales, and production suspensions that affected workforce utilization [4].

When organizations are experiencing supply chain disruptions, the ability to manage resources and reconfigure them according to the environmental setting is critical for firm survival [32]. AI enables a data-driven approach to forecast trajectories using machine- learning. Consequently, AI tools and applications can be used to improve the resilience of supply chain operations through a modeling approach to predict risks and assess vulnerability [4].

Since a firm's coordinating/integration capability involves processes of gathering and interpreting data, allocating resources and tasks, and communicating decision and information [15], AI directed to these processes may help firms be more aware that disruptions can occur based on past experience and learn from prior disruptions. Consequently, it will lead to high firm resilience. Further, a firm's learning capability is dynamic and multilevel. This capability can promote, enhance, and renew technological knowledge [15] that is critical during supply chain disruptions. Firms that emphasize on learning are able to reconfigure and realign their resources and processes to develop capabilities [33]. The ability to utilize AI for learning can significantly enhance the firm's capability to cope with anticipated disruptions, sense and respond quickly and appropriately to changing conditions [12]. Lastly, if firms can quickly reshape its asset base and effectively evaluate markets' and competitors' move, they are likely to have a better capability in managing resources to respond to disruptions [1]. Optimization and simulation models provided by AI technologies targeted to enhance strategies competitive response capability allow firms to conduct a robust supply chain design and resilience analysis. Taken together, AI is an important tool needed to implement resilience strategies [34].

AI's ability to process a large amount of information facilitates overall organizational learning capability [16] and decision-making processes [35] that may lead to the deployment of contingency plans to deal with challenges posed by organizational and supply chain disruptions. Furthermore, AI could be used to identify organizational slack resources (e.g., material, financial, social, network, and intangible resources), which could then be reconfigured to help solve issues generated by disruptions [36]. Moreover, AI could help managers understand their competitive environment and their patterns of change, and thus taking all the required actions to respond to change [37]. Thus, we can hypothesize:

H1: AI use positively influences firm resilience to supply chain disruptions

\subsection{Firm Resilience and Firm Performance}

Prior research has shown that supply chain disruptions directly and indirectly impacted supply chain performance, lowering both stock returns and firms' competitive advantage [4]. Organizational resilience reduces the firm's vulnerability to supply chain disruptions or quickly recover from them if they 
occurred [1]. This organizational resilience for supply chain disruptions could be viewed as the firm's capability to "be alert to, adapt to, and quickly respond to changes brought by a supply chain disruption" $[1, \mathrm{p}$. 112]. It allows a firm to keep its operations running during disruptions and thus increases firm performance [38].

In this study, we postulate that AI use will enhance firm resilience, which in turn, will improve firm's operational performance. Because AI use for coordination, learning, and strategic responses is embedded in organizational routines (i.e., organizational practices and processes that utilize clusters of resources to achieve desired outcomes), such usage enables organizations to renew firm-level and supply-chain resources to endure or respond to changes [39]. AI helps firms detect threats, either from the external business environment or from the internal supply chain network in a timely manner. Consequently, firms can flexibly inspect goods and information flows from one end of the supply chain to the other. As firms are able to identify operational risks in a timely manner, AI use directed to improve coordination, learning, and strategic response can reduce potential financial losses caused by supply chain disruptions. Thereby, we hypothesize that AI use influences firm performance through firm resilience to supply chain disruptions.

H2: Firm resilience to supply chain disruptions positively mediates the relationship between AI use and firm performance

\subsection{AI Use and Firm Performance}

Although we hypothesize that firm resilience to supply chain disruptions will mediate the relationship between AI use and firm performance, we also hypothesize that AI use may have a direct impact on firm performance. By offering new insights in various areas (e.g., customer insights, marketing, supply chains, operations, etc.), the use of AI enhances firm's operational performance and enables firms to continually develop a series of temporary advantages in supply chain. For example, business are increasingly making use of AI systems to overcome information processing constraints inherent to supply chain, resulting in innovative paths of designing new products, solving supply chain issues and satisfying customers, and eventually, improving firm performance [9].

Empirical studies that established the link between AI use and firm performance are emerging. For example, Mikalef and Gupta [40] conceptualized AI capability as a high-order construct encompassing several dimensions, including tangible resources, human skills, and intangible resources. Then, they found a positive and significant relationship between AI and organizational performance. Similarly, Dubey et al. [41] found that AI usage enables analytics capabilities that has a positive and significant impact on firm operational performance. In other words, we suggest that the more a firm is endowed with capabilities to use AI to establish dynamic capabilities that enable it to coordinate its resources, enhance and renew technological knowledge, and modify its resource base, the higher its performance will be. Therefore, we hypothesize that:

\section{H3: AI use positively influences firm performance}

\section{Research Method}

To test the research hypotheses, we conducted a two-stage survey to collect data from business and IT executives in Europe (i.e., United Kingdom and France) through a questionnaire. We measured AI use and the control variables at one point in time (t1) and measured firm resilience and firm performance at a second point in time (t2). The first survey was conducted in November 2020, and the second survey was completed by the same respondents four months after the first survey. Of 225 respondents who completed the first survey, a total of 107 respondents completed the second survey for an effective response rate 47.5 percent. Our unit of analysis is an organizational level. Only firms that had adopted AI systems (i.e., virtual agents, machine learning platforms, deep learning platforms, robotic process automation) in their supply chain and business processes at the time of the survey were eligible to participate.

The questionnaire was developed based on prior literature, with items being adapted from previously tested instruments. Items to measure three dimensions of AI use were adapted from Protogerou et al. [15]. Coordination capability was measured using three items (e.g., in our firm, AI tools and applications have facilitated integration and standardization of business process); learning capability was measured using three items (e.g., in our firm, AI tools and applications have facilitated organized processes of in-house learning and knowledge development); and strategic competitive response capability was measured using four items (e.g., in our firm, AI tools and applications have facilitated timely response to competitive strategic moves). Firm resilience's scale was adapted from Ambulkar et al. [1] (e.g., during COVID-19 pandemic, we were able to maintain high situational awareness at all times; we were able to provide a quick response to the supply chain disruption). Lastly, firm performance, which directed to measure operational performance, was measured using five items adapted from Queiroz et al. [31] (e.g., indicate your firm's performance during the last 12 years relative to all other competitors in terms of (1) timeliness of delivery, (2) high-quality supply, (3) 
response time, (4) operating efficiency, and (5) process improvement). All items used to measure the focal constructs were measured using a 7-point Likert scale. Respondents' IT and business knowledge were measured by asking respondents two questions - each on how knowledgeable they were about their company's IT and business strategies using a 5-point Likert scale. The questionnaire was first tested using IT professionals recruited in Prolific.co. We then revised the questionnaire based on the comments received from the pilot testing.

We decided to use a single informant from each organization for several reasons. First, using multiple informants per organization would have an adverse effect on our sample size [42]. Second, collecting data using multiple informants can create potential bias (e.g., executive may have doubts that the responses will be truly anonymous) [42]. Additionally, collecting data using multiple informants may result in subjectivity and measurement errors [43].

Questionnaires were electronically distributed to members of an online panel managed by a market research company. Companies located in UK and France were the target of our surveys. A total of 107 respondents completed survey $\mathrm{t} 1$ and survey $\mathrm{t} 2$. Given the questions being asked were related to $\mathrm{AI}$ and its consequences, we targeted either business or IT executives with high levels of shared domain knowledge (i.e., high business and IT knowledge). Demographic information collected suggested that the respondents were reliable sources. On average, respondents' levels of business and IT knowledge were 3.88 and 3.87, respectively (on a 5-point Likert Scale); had more than 5 years of experience in their managerial positions, and more than 84 percent of the respondents had at least an undergraduate degree or higher. The demographics of our sample reveal that over 68 percent of firms were based in France. The median firm size was 501-1000 employees, and the median firm age was over 15 years.

To assess potential nonresponse bias in survey one, we employed wave analysis [44]. Responding firms were grouped into early and late respondents, and comparisons were made along respondent's age, gender, education, firm size, and firm age. Our analysis demonstrated that no significant differences between early and late respondents. Responding and nonresponding firms were compared along the same criteria for the second survey. Again, there were no significant differences between responding and nonresponding firms. Based on these findings, we conclude that nonresponse bias is not a major concern in this study.

\section{Data Analysis and Results}

We analyzed the survey data using partial least square (PLS) with a two-step analytic approach. First, the measurement model was evaluated to assess the validity and reliability of the measures. Second, the structural model was evaluated to test the hypotheses. The psychometric properties of all scales were assessed within the context of the structural model through an assessment of discriminant validity and reliability.

\subsection{Measurement Model}

Following Protogerou et al. [15], we conceptualize AI use as a reflective, second order construct. A reflective second-order measurement model was estimated to arrive at a representative holistic construct using coordination, learning, and strategic competitive response capabilities as first-order constructs.

The psychometric properties of the scales are assessed in terms of item loadings, internal consistency, and discriminant validity. Item loadings and internal consistencies greater than .70 are generally considered acceptable [45]. As summarized in Table 2, the scales used in the study largely meet these guidelines. All indicators also loaded more strongly on their corresponding constructs than on other constructs, suggesting high discriminant validity.

Table 2. Item Loadings, Compositive Reliability, and AVE

\begin{tabular}{l|c|c|c|c|c}
\multicolumn{1}{c|}{ Item } & CR & AVE & AI Use & OR & FP \\
\hline Coordination_t1 & .95 & .67 & $\mathbf{. 9 6}$ & .42 & .35 \\
Learning_t1 & & & $\mathbf{. 9 1}$ & .37 & .30 \\
CompResponse_t1 & & & $\mathbf{. 9 2}$ & .46 & .28 \\
\hline OrgResilience1_t2 & .92 & .71 & .15 & $\mathbf{. 7 0}$ & .24 \\
OrgResilience2_t2 & & & .37 & $\mathbf{. 8 3}$ & .35 \\
OrgResilience3_t2 & & & .32 & $\mathbf{. 8 6}$ & .48 \\
OrgResilience4_t2 & & & .48 & $\mathbf{. 9 1}$ & .47 \\
OrgResilience5_t2 & & & .44 & $\mathbf{. 8 9}$ & .51 \\
\hline FP1_t2 & .92 & .69 & .28 & .48 & $\mathbf{. 8 4}$ \\
FP2_t2 & & & .14 & .39 & $\mathbf{. 8 0}$ \\
FP3_t2 & & & .29 & .49 & $\mathbf{. 8 4}$ \\
FP4_t2 & & & .32 & .32 & $\mathbf{. 7 7}$ \\
FP5_t2 & & & .33 & .43 & $\mathbf{. 9 0}$ \\
\hline
\end{tabular}

$C R=$ Compositive Reliability; $A V E=$ Average Variance Extracted; $t 1=$ Measured at the first stage of survey; $t 2=$ Measured at the second stage of survey.

To further assess discriminant validity, the average variance extracted (AVE) should be larger than the inter-construct correlations [46]. As shown by the comparison of inter-construct correlations and AVE (bold numbers on the leading diagonal) in Table 3 , the constructs meet this guideline, pointing to the discriminant validity of the constructs in the model. 
Table 3. Correlation Matrix

\begin{tabular}{lllllllll}
\hline & $\mathbf{1}$ & $\mathbf{2}$ & $\mathbf{3}$ & $\mathbf{4}$ & $\mathbf{5}$ & $\mathbf{6}$ & $\mathbf{7}$ & $\mathbf{8}$ \\
\hline 1. AI Use & .93 & & & & & & & \\
2. Org. Res & $.45^{* *}$ & $\mathbf{. 8 4}$ & & & & & & \\
3. FP & $.33^{* *}$ & $.51^{* *}$ & $\mathbf{. 8 3}$ & & & & & \\
4. BuKnow & $.39^{* *}$ & $.21^{* *}$ & .10 & $\mathrm{NA}$ & & & & \\
5. ITKnow & $.29^{* *}$ & $.32^{* *}$ & .13 & $.54^{* *}$ & $\mathrm{NA}$ & & & \\
6. Resp. Position & -.14 & $-.18^{*}$ & .01 & $-.34^{* *}$ & -.20 & $\mathrm{NA}$ & & \\
7. FirmAge & -.10 & -.02 & -.06 & .03 & .10 & $.19^{*}$ & $\mathrm{NA}$ & \\
8. FirmSize & -.01 & .13 & .02 & $-.17^{*}$ & -.05 & $.32^{* *}$ & $.26^{* *}$ & $\mathrm{NA}$ \\
\hline${ }^{* *} p<.01 ;{ }^{*} p<.05$ & & & & & & & &
\end{tabular}

In addition to establishing measurement reliability and validity, it is important to consider the potential effects of common method bias. For several reasons, common method bias is not likely to be a source of bias in this study. First, the potential for common method bias is lessened somewhat by the fact that we gathered the data in two different time periods [47]. Second, the correlation scores among the focal constructs are relatively low. These observed correlations provide evidence that common method bias is not prevalent [48]. Third, we conducted two statistical tests to assess the potential of common method bias, including Harman's single-factor test [47] and the marker variable technique [49]. Both tests suggest that common method bias does not appear to be problematic. Based on the study design and various statistical tests, we therefore conclude that the probability of common method bias is minimal and is unlikely to bias the findings of our study.

\subsection{Structural Model}

The structural model is presented in Figure 2. The findings showed that AI use had a direct effect on firm resilience to supply chain disruptions, supporting H1. We performed a mediation test to examine the mediation role of firm resilience. The indirect effect of AI use on firm performance through firm resilience was significant $(.22, p<.001)$, supporting $\mathrm{H} 2$. However, the direct effect (after firm resilience was added to the model) was not significant $(\beta=.14, p=.10)$. These results suggest that firm resilience fully mediated the relationship between AI use and firm performance. Thus, $\mathrm{H} 3$ was not supported.

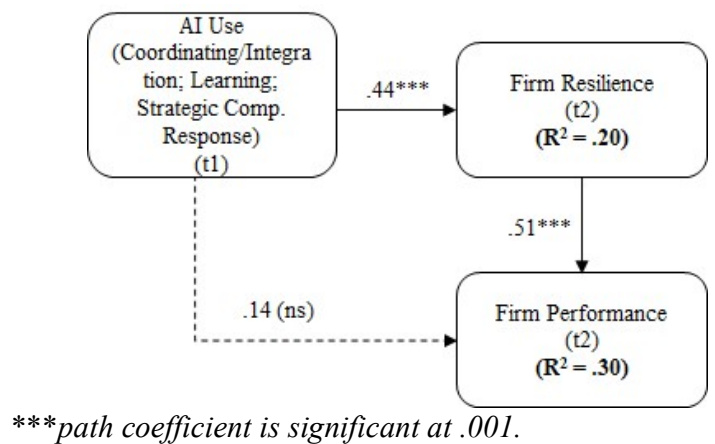

Figure 2. Structural Model

\section{Discussions}

The current study investigates how the firm ability to use AI's information processing capability directed toward three core activities: coordination, learning, and strategic responses influences firm resilience, and in turn, firm performance. Our examination of the mediating effect of firm resilience provides a more thorough discussion on how AI use may indirectly influence firm performance. The insignificant direct effect of AI use on firm performance suggests that AI use is not necessarily linked to firm performance, but foremost to the firm ability to reconfigure its resources using AI that facilitates firm resilience to supply chain disruptions. The findings of our study specify that AI use can create value indirectly by enhancing firm resilience (i.e., its impact on firm performance is fully mediated by firm resilience).

\subsection{Theoretical contributions and implications}

Supply chain has always been affected by predictable or unforeseen events that threaten firm's profitability and continuity [50]. In our study, we present a clear definition of AI's information processing capability as a source of dynamic capabilities that influences firm resilience to supply chain disruptions. In today's highly networked business environments, AI's information processing capability enable firms to capitalize and compete by increasing the exploitation of ideas and information. AI enables faster and more complete information processing, leading to more accurate predictions that give decision makers greater advanced notice of the need to adjust resource allocations when disruption events take place. AI directed toward the following three areas: coordination, learning, and strategic competitive responses, leads to stronger firm resilience.

Our findings extend the IS literature as well as supply chain disruptions literature to include a better understanding of the importance of emerging technologies such as AI for firm resilience. For example, many recent studies have demonstrated the negative impact of COVID-19 pandemic on the supply chain of many companies from various industries, and how firm resilience can minimize such impact (e.g., [51]; [52]; [53]). Our findings contribute to the existing studies by demonstrating that emerging technologies such as AI can help organizations be more resilience to supply chain disruptions. AI use enables firms to reconfigure their resources in the face of disruptions. These findings support the notion that although it is important for a firm to have resources to be resilient, 
resources themselves cannot guarantee resilience [1]. AI directed to reconfigure resources through its information processing capability is critical to firm resilience. When facing a disruption, firms that are able to utilize AI to evaluate their current resource base (e.g., predicting future supply and demand), provide insights for decision-making processes, and support organization learning are likely to quickly recover from the disruption.

Our findings show that AI use does not have a direct impact on firm performance. Although prior research has demonstrated a significant direct effect of emerging technology usage such as big data analytics on firm performance (e.g., [54]), these studies did not consider firm resilience as a mediator. Theoretically, dynamic capabilities do not engage in the production of marketable good or service $[14 ; 15]$. Instead, they build, integrate, and reconfigure existing resources [14] that are needed during the time of high uncertainty. Facing disruptions, organizations may sense new threats and opportunities and may need to renew, reconfigure or realign their risk management infrastructure. AI provides firms with new insights and new ways to deal with disruptions. Lack of firm resilience will lead to low firm performance, despite high AI use. Therefore, firm resilience mediates the relationship between AI use and firm performance.

Further, our research contributes to the dynamic capability literature. We conceptualize AI use as a dynamic organizational information processing capability that can influence key aspects of firm resilience to supply chain disruptions. Unlike technology in the past, AI has greater autonomy and deeper learning capacity [25]. Such AI capabilities could revolutionize industries and change a firm's competitive environment. Our study demonstrates that when firms are able to direct AI's information processing to coordinating/integration, learning, and strategic competitive responses, they become more flexible to meet the demands of surviving in a changing environment.

\subsection{Limitations and Future Research}

We note several potential limitations of the study. First, we conducting the data collecting when the COVID-19 pandemic was in effect. Data collected preor post-pandemic may yield different results as firms operate in a less-dynamic environment. It would be interesting to examine the relationship between AI use and firm performance when firms operate in a more stable environment.

Second, we used self-reported data to test the model. Although considerable efforts were made to ensure data quality, the potential of survey biases cannot be excluded. Future research is needed to elaborate objective performance data with self-report data.

Third, our study relies on members of top management team as the key informants. Although we measured their level of IT and business knowledge, future research sampling multiple informants will be helpful to improve the validity of our study.

Despite all these limitations, this study is the first to use a two-stage survey approach at the organizational level to study the impact of AI use. The study extends the existing body of knowledge on organization-level IT adoption. Specifically, we focus on AI use as a dynamic capability consisting of three core processes. We also provide more insights into the nature of the relationship among AI use, firm resilience, and firm performance.

\subsection{Practical implications}

The results of this study have several important implications for managerial practices. First, as adoption of AI continues to increase and many organizations now use AI systems to generate some business value, they are still struggling to build AI capabilities that can lead to increased firm performance [12]. Interestingly, our findings show that the effect of AI use on firm performance is mediated by firm resilience to supply chain disruptions. Following the COVID-19 outbreak, firm resilience is at the forefront of the C-suite's agenda these days [9]. Senior-level managers and decision makers should take note of the importance of establishing firm resilience using AI. AI use can be a starting point for establishing firm resilience as it assists management in establishing and reconfiguring critical resources.

Organizational decision makers should also focus on directing AI use to build dynamic capabilities. It isn't AI use itself that leads to firm performance, but the ways organizations use AI to coordinate resources, learn, and respond to opportunities during disruptive events that matter. Organizational decision makers should be aware that embedding AI systems into business operations and supply chain activities can drive firm resilience-a firm's situational capability acquire through continuous learning and adaptations [9].

\section{Conclusions}

In conclusion, our study focuses on investigating how AI use influences firm resilience to supply chain disruptions and, in turn, firm performance. Through a longitudinal study of organizations that had adopted AI in their business practices, we show that firm resilience to supply chain disruptions mediates the relationship between AI use and firm performance. We hope that this 
paper lays the groundwork for future research concerning the business value of AI.

\section{References}

[1] Ambulkar, S., Blackhurst, J., and Grawe, S. (2015). "Firm's resilience to supply chain disruptions: Scale development and empirical examination," Journal of Operations Management, 33, pp. 111-122.

[2] Michelman, P. (2007). "Building a resilient supply chain," Harward Business Review. Retrieved from https://hbr.org/2007/08/building-a-resilient-supply-ch.

[3] Craighead, C. W., Blackhurst, J., Rungtusanatham, M. J., \& Handfield, R. B. (2007). "The severity of supply chain disruptions: Design characteristics and mitigation capabilities," Decision Sciences, 38(1), pp. 131-156.

[4] Ivanov, D., and Dolgui, A. (2020). "A digital supply chain twin for managing the disruption risks and resilience in the era of Industry 4.0." Production Planning \& Control, 32(9), pp. 1-14.

[5] Linton, T., and Vakil B. (2020). "Coronavirus is proving we need more resilient supply chains," Harvard Business Review. Retrieved from https://hbr.org/2020/03/coronavirus-is-proving-that-weneedmore-resilient-supply-chains.

[6] Wieland, A., and Wallenburg, C. M. (2013). "The influence of relational competencies on supply chain resilience: A relational view," International Journal of Physical Distribution \& Logistics Management, 43(4), pp. 300-320.

[7] McKinsey \& Company. (2021). "Succeeding in the AI supply-chain revolution," Retrieved from https://www.mckinsey.com/industries/metals-andmining/our-insights/succeeding-in-the-ai-supply-chainrevolution.

[8] Gu, M., Yang, L., and Huo, B. (2021). "The impact of information technology usage on supply chain resilience and performance: An ambidextrous view," International Journal of Production Economics, 232, 107956.

[9] Belhadi, A., Mani, V., Kamble, S. S., Khan, S. A. R., and Verma, S. (2021). "Artificial intelligence-driven innovation for enhancing supply chain resilience and performance under the effect of supply chain dynamism: An empirical investigation," Annals of Operations Research, In-press.

[10] Benbya, H., Davenport, T. H., \& Pachidi, S. (2020). "Special issue editorial. artificial intelligence in organizations: Current state and future opportunities," MIS Quarterly Executive, 19(4), pp. ix-xxi.

[11] Burian, J. (2021). "The complex choreography of supply chain resilience," Industry Week (May $7^{\text {th }}$ ), Retrieved from https://www.industryweek.com/supply-

chain/article/21163467/supply-chain-resilience-is-amultilevel-challenge.

[12] Ransbotham, S., Khodabandeh, S., Kiron, D., Candelon, F., Chu M., \& Lafountain, B. (2020). "Expanding AI's impact with organizational learning," MIT Sloan Management Review (October 19 ${ }^{\text {th }}$ ), Retrieved from https://sloanreview.mit.edu/projects/expanding-ais-impactwith-organizational-learning/.
[13] Von Krogh, G. (2018). "Artificial intelligence in organizations: New opportunities for phenomenon-based theorizing," Academy of Management Discoveries, 4(4), pp. 404-409.

[14] Teece, D. J., Pisano, G., and Shuen, A. (1997). "Dynamic capabilities and strategic management," Strategic Management Journal, 18(7), pp. 509-533.

[15] Protogerou, A., Caloghirou, Y., and Lioukas, S. (2012). "Dynamic capabilities and their indirect impact on firm performance," Industrial and Corporate Change, 21(3), pp. 615-647.

[16] Rai, A., Constantinides, P., and Sarker, S. (2019). "Next Generation Digital Platforms: Toward Human-AI Hybrids," MIS Quarterly, 43(1), pp. iii-ix.

[17] Grover, P., Kar, A. K., and Dwivedi, Y. K. (2020). "Understanding artificial intelligence adoption in operations management: Insights from the review of academic literature and social media discussions," Annals of Operations Research, in-press, pp. 1-37.

[18] Sturm, T., Gerlach, J., Pumplun, L., Mesbah, N., Peters, F., Tauchert, C., ... \& Buxmann, P. (2021). "Coordinating human and machine learning for effective organizational learning," MIS Quarterly, 45(3), pp. 1581-1602.

[19] Davenport, T. H., \& Ronanki, R. (2018). "Artificial intelligence for the real world," Harvard Business Review, 96(1), pp. 108-116.

[20] Benbya, H., Pachidi, S., and Jarvenpaa, S. L. (2021). "Artificial intelligence in organizations: implications for information systems research," Journal of the Association for Information Systems, 22(2), In-press.

[21] Tushman, M.L. and Nadler, D.A. (1978). "Information processing as an integrating concept in organizational design," Academy of Management Review, (3:3), pp. 613624.

[22] Zhu, S., Song, J., Hazen, B. T., Lee, K., \& Cegielski, C. (2018). "How supply chain analytics enables operational supply chain transparency: An organizational information processing theory perspective," International Journal of Physical Distribution \& Logistics Management, 48(1), pp. 47-68.

[23] Teece, D., Peteraf, M., and Leih, S. (2016). "Dynamic capabilities and organizational agility: Risk, uncertainty, and strategy in the innovation economy," California Management Review, 58(4), pp. 13-35.

[24] Lawless, W. F., Mittu, R., Sofge, D., and Hiatt, L. (2019). Artificial intelligence, autonomy, and human-machine teams: interdependence, context, and explainable AI. AI Magazine, 40(3), pp. 5-13.

[25] Berente, N., Gu, B., Recker, J., \& Santhanam, R. (2021). "Managing artificial intelligence," MIS Quarterly, 45(3), pp. 1433-1450.

[26] Grønsund, T., and Aanestad, M. (2020). "Augmenting the algorithm: Emerging human-in-the-loop work configurations," Journal of Strategic Information Systems, 29(2), 101614.

[27] Faraj, S., Pachidi, S., and Sayegh, K. (2018). "Working and organizing in the age of the learning algorithm," Information and Organization, 28(1), pp. 62-70.

[28] Kruger, G. H., Shih, A. J., Hattingh, D. G., and van Niekerk, T. I. (2011). "Intelligent machine agent architecture for adaptive control optimization of 
manufacturing processes," Advanced Engineering Informatics, 25(4), pp. 783-796.

[29] Tsuchiya, S. (1993). Artificial intelligence and organizational learning: How can ai contribute to organizational learning. AAAI Technical Report WS-9303 .

[30] Salovaara, A., Lyytinen, K., and Penttinen, E. (2019). "High reliability in digital organizing: Mindlessness, the frame problem, and digital operations," MIS Quarterly, 43(2), pp. 555-578.

[31] Queiroz, M. M., \& Telles, R. (2018). "Big data analytics in supply chain and logistics: An empirical approach," International Journal of Logistics Management, 29(2), pp. 767-783.

[32] Sirmon, D.G., Hitt, M.A., 2003. "Managing resources: Linking unique resources, management and wealth creation in family firms," Entrepreneurship Theory and Practice, 27(4), pp. 339-358.

[33] Helfat, C. E., and Peteraf, M. A. (2003). "The dynamic resource-based view: Capability lifecycles," Strategic Management Journal, 24(10), pp. 997-1010.

[34] Chowdhury, P., Paul, S. K., Kaisar, S., and Moktadir, M. A. (2021). "COVID-19 pandemic related supply chain studies: A systematic review," Transportation Research Part E: Logistics and Transportation Review, 148, 102271.

[35] Cao, G., Duan, Y., Edwards, J. S., and Dwivedi, Y. K. (2021). 'Understanding managers' attitudes and behavioral intentions towards using artificial intelligence for organizational decision-making," Technovation, 6, 102312.

[36] Pal, R., Torstensson, H., and Mattila, H. (2014). "Antecedents of organizational resilience in economic crises - an empirical study of Swedish textile and clothing SMEs," International Journal of Production Economic, 147, pp. 410-428.

[37] Kamalahmadi, M., \& Parast, M. M. (2016). "A review of the literature on the principles of enterprise and supply chain resilience: Major findings and directions for future research," International Journal of Production Economics, 171, pp. 116-133.

[38] Macdonald, J. R., Zobel, C. W., Melnyk, S. A., and Griffis, S. E. (2018). "Supply chain risk and resilience: theory building through structured experiments and simulation," International Journal of Production Research, 56(12), pp. 4337-4355.

[39] Li, X., Wu, Q., Holsapple, C. W., and Goldsby, T. (2017). "An empirical examination of firm financial performance along dimensions of supply chain resilience," Management Research Review, 40(3), pp. 254-269.

[40] Mikalef, P., and Gupta, M. (2021). "Artificial intelligence capability: Conceptualization, measurement calibration, and empirical study on its impact on organizational creativity and firm performance," Information \& Management, 58(3), 103434.

[41] Dubey, R., Gunasekaran, A., Childe, S. J., Bryde, D. J., Giannakis, M., Foropon, C., ... and Hazen, B. T. (2020). "Big data analytics and artificial intelligence pathway to operational performance under the effects of entrepreneurial orientation and environmental dynamism: A study of manufacturing organizations," International Journal of Production Economics, 226, 107599.
[42] Kearns, G. S., and Sabherwal, R. (2006). "Strategic alignment between business and information technology: A knowledge-based view of behaviors, outcome, and consequences," Journal of management information systems, 23(3), pp. 129-162.

[43] Gerow, J. E., Grover, V., Thatcher, J., and Roth, P. L. (2014). "Looking toward the future of IT-business strategic alignment through the past," MIS Quarterly, 38(4), pp. 1159-1186.

[44] Armstrong, J. S., and Overton, T. S. (1977). "Estimating nonresponse bias in mail surveys," Journal of Marketing Research, 14(3), pp. 396-402.

[45] Fornell, C., and Larcker, D. F. (1981). "Structural equation models with unobservable variables and measurement error: algebra and statistics," Journal of Marketing Research, 18(3), pp. 382-388.

[46] Chin, W. 1998. The partial least squares approach to structural equation modeling. G. A. Marcoulides (ed). Modern Methods for Business Research. Erlbaum Assoc., Mahwah, NJ, pp. 295-336.

[47] Podsakoff, P. M., MacKenzie, S. B., Lee, J. Y., and Podsakoff, N. P. (2003). "Common method biases in behavioral research: a critical review of the literature and recommended remedies," Journal of Applied Psychology, 88(5), pp. 879-903.

[48] Craighead, C. W., Ketchen, D. J., Dunn, K.S., and Hult, G. T. M. (2011). "Addressing common method variance: Guidelines for survey research on information technology, operations, and supply chain management," IEEE Transactions on Engineering Management, 58(3), pp. 578588.

[49] Lindell, M., and Whitney, D. (2001). "Accounting for common method variance in cross sectional research designs," Journal of Applied Psychology, 8, pp. 114-121.

[50] Baryannis, G., Validi, S., Dani, S., \& Antoniou, G. (2019). "Supply chain risk management and artificial intelligence: State of the art and future research directions," International Journal of Production Research, 57(7), pp. 2179-2202.

[51] Ali, M. H., Suleiman, N., Khalid, N., Tan, K. H., Tseng, M. L., and Kumar, M. (2021). "Supply chain resilience reactive strategies for food SMEs in coping to COVID-19 crisis," Trends in Food Science \& Technology, 109, pp. 94-102.

[52] Belhadi, A., Kamble, S., Jabbour, C. J. C., Gunasekaran, A., Ndubisi, N. O., and Venkatesh, M. (2021). "Manufacturing and service supply chain resilience to the COVID-19 outbreak: Lessons learned from the automobile and airline industries," Technological Forecasting and Social Change, 163, 120447.

[53] Ivanov, D., and Dolgui, A. (2020). "Viability of intertwined supply networks: extending the supply chain resilience angles towards survivability. A position paper motivated by COVID-19 outbreak," International Journal of Production Research, 58(10), pp. 2904-2915.

[54] Wamba, S. F., Dubey, R., Gunasekaran, A., \& Akter, S. (2020). "The performance effects of big data analytics and supply chain ambidexterity: The moderating effect of environmental dynamism," International Journal of Production Economics, 222, 107498. 